Check for updates

Cite this: Chem. Sci., 2019, 10, 464

๑ All publication charges for this article have been paid for by the Royal Society of Chemistry

Received 30th August 2018

Accepted 13th October 2018

DOI: $10.1039 / c 8 s c 03877 e$

rsc.li/chemical-science

\section{Carved nanoframes of cobalt-iron bimetal phosphide as a bifunctional electrocatalyst for efficient overall water splitting $\dagger$}

\author{
Yuebin Lian, ${ }^{\mathrm{ab}}$ Hao Sun, ${ }^{\mathrm{ab}}$ Xuebin Wang, ${ }^{\mathrm{ab}}$ Pengwei Qi, ${ }^{\mathrm{ab}}$ Qiaoqiao Mu, ${ }^{\mathrm{ab}}$ Yujie Chen, ${ }^{\mathrm{ab}}$ \\ Jing $\mathrm{Ye}^{\mathrm{C}}$ Xiaohui Zhao, ${ }^{\text {ab }}$ Zhao Deng (D) *ab and Yang Peng (D) *ab
}

\begin{abstract}
Water electrolysis for hydrogen production has long been regarded as an ideal tactic for renewable energy conversion and storage, but is impeded by the sluggish kinetics of both the hydrogen and oxygen evolution reactions, which are therefore in urgent need for high-performance but low-cost electrocatalysts. Herein, nanoframes of transition metal phosphides (TMPs) with the 3D framework carved open have been demonstrated as highly potent bifunctional catalysts for overall water splitting, reaching the benchmark performance of the $\mathrm{Pt} / \mathrm{C} \| \mathrm{RuO}_{2}$ couple, and are much superior to their nanocubic counterparts. This excellent water splitting behavior can be attributed to the enlarged active surface area, less obstructed electrolyte infiltration, promoted charge transfer, and facilitated gas release. Further through in-depth activity analysis and post-electrocatalysis characterization, special attention has been paid to the fate and role of phosphorus in the electrocatalytic process, suggesting that despite the chemical instability of the TMPs (especially under OER conditions), excellent electrocatalytic stability can still be achieved through the amorphous bimetallic hydroxides/oxides formed in situ.
\end{abstract}

\section{Introduction}

Water electrolysis for hydrogen production offers a promising solution to convert and store intermittent clean energy resources such as wind, tidal, solar $e t c$. in a scalable fashion..$^{1,2}$ It involves a hydrogen evolution reaction (HER) at the cathode and an oxygen evolution reaction (OER) at the anode, both of which are kinetically sluggish and in urgent need for highly active electrocatalysts to expedite the redox electron transfer. ${ }^{3-7}$ So far, the state-of-the-art candidates in this regard have been catalysts based on noble metals (e.g. Pt for the $\mathrm{HER}$ and $\mathrm{RuO}_{2} / \mathrm{IrO}_{2}$ for the OER), but their exorbitant cost and scarcity greatly limit broader applications. Moreover, using different catalysts for each side of the water splitting reaction will unavoidably increase the material and processing costs, and therefore bifunctional catalysts based on earth-abundant elements with low fabrication costs are highly desirable. In such contexts, considerable efforts have been made to develop high-efficiency bifunctional electrocatalysts for overall water splitting, including metals, ${ }^{\mathbf{8} 9}$

\footnotetext{
${ }^{a}$ Soochow Institute for Energy and Materials Innovations, College of Energy, Soochow University, Suzhou 215006, P. R. China

${ }^{b}$ Key Laboratory of Advanced Carbon Materials and Wearable Energy Technologies of Jiangsu Province, Soochow University, Suzhou 215006, P. R. China. E-mail: zdeng@ suda.edu.cn; ypeng@suda.edu.cn

${ }^{c}$ Analysis and Testing Center, Soochow University, Suzhou 215123, China

$\dagger$ Electronic supplementary information (ESI) available. See DOI: $10.1039 / \mathrm{c} 8 \mathrm{sc} 03877 \mathrm{e}$
}

alloys ${ }^{10,11}$ metal oxides, ${ }^{12,13}$ metal nitrides,${ }^{14}$ metal chalcogenides, ${ }^{15,16}$ metal carbides, ${ }^{17-20}$ metal hydroxides, ${ }^{21-23}$ etc. However, more advancement is imperative to further reduce the energy input and maximize the current density in the electrolysis process for practical implementation.

Transition-metal phosphides (TMPs), such as $\mathrm{Ni}_{2} \mathrm{P}^{24,25}$ $\mathrm{CoP}^{, 26,27} \mathrm{FeP},{ }^{28-30} \mathrm{RuP}_{2},{ }^{31} \mathrm{Cu}_{3} \mathrm{P}^{32}$ etc., emerge as a new class of noble-metal-free catalysts for electrochemical water splitting, owing to their low fabrication cost, good electrochemical stability, controllable valence of central metals, and suitable bonding energy for the intermediates of both the HER and OER. ${ }^{33,34}$ To further enhance the electrochemical performance, research has been progressing to extend from mono-metallic to multi-metallic phosphides by doping one or more metal atoms, aiming for optimizing both the electronic structure and surface potential of the catalysts. As a result, high-activity catalysts with reduced overpotential and enhanced exchange current have been achieved. Despite all that, further insights into the role and fate of phosphorus in such catalysts during electrolysis are still lacking and thus highly desired for fundamental understanding of the catalytic mechanism and electrolytic process. In addition, while most of the previous studies on TMPs mainly dealt with half reactions (either the HER or OER), their applications in overall water splitting have been still limited and need to be realized with extended stability. ${ }^{35,36}$

The structural framework and surface morphology of nanomaterials are important prerequisites for determining the exposure of active sites and the activity of individual catalytic 
sites, which ultimately impart the overall catalytic potency. ${ }^{37,38}$ TMP nanostructures with the morphology of nanoparticles, ${ }^{39}$ nanosheets, ${ }^{40}$ nanowires ${ }^{41}$ etc., owing to their high porosity and specific surface area for promoting electrolyte infiltration and contact, have been demonstrated as efficient electrocatalysts for accelerating both the HER and OER. For example, Lou et al. fabricated Ni-Co-P nanobricks with oriented nanosheets as the bifunctional electrocatalyst for overall water splitting, and achieved a low cell voltage of $1.62 \mathrm{~V}$ for reaching a current density of $10 \mathrm{~mA} \mathrm{~cm}{ }^{-2} \cdot{ }^{42}$ Using MOF-74 as the structural precursor, Zhao et al. synthesized a series of Co-Ni-P catalysts, with the best composition of $\mathrm{Co}_{4} \mathrm{Ni}_{1} \mathrm{P}$ in the form of nanotubes affording a current density of $10 \mathrm{~mA} \mathrm{~cm} \mathrm{~cm}^{-2}$ at a cell voltage of $1.59 \mathrm{~V}^{43}$ Recently, nanostructures with the open framework such as nanocages ${ }^{44}$ and nanoframes ${ }^{45}$ as electrocatalysts have drawn further interests because of the facilitated charge and mass transportation, and the increased defective surface sites, both leading to greatly enhanced reaction kinetics. Hence, it can be rationalized that open frameworks of TMPs, in comparison to their bulky counterparts, should exhibit superior catalytic performance towards efficient water splitting.

To testify this hypothesis, herein, we adopt bimetallic MOF Co-Fe Prussian Blue Analogues (Co-Fe PBAs) as the structural template, followed by etching with urea and phosphorizing with sodium hypophosphite, and fabricate nanoframes of Co-Fe phosphides for use as the bifunctional electrocatalyst for overall water splitting. The obtained $\mathrm{Co}_{0.6} \mathrm{Fe}_{0.4} \mathrm{P}$ nanoframes inherit the uniform cubic structure of PBAs with open 3D frameworks, which effectively promote the electroactive surface area, as well as the charge and mass transportation. In addition, the utilization of MOFs as the structural precursor allows the homogeneous distribution of various metal centers in a conductive and protective carbon matrix. As a result, with an optimized etchant dosage excellent HER and OER activities were simultaneously achieved, outperforming most of the TMP-based catalysts reported to date..$^{35,46-48}$ What's more, our bifunctional catalyst needs only $1.57 \mathrm{~V}$ to achieve $10 \mathrm{~mA} \mathrm{~cm}{ }^{-2}$ for overall water splitting with excellent long-term stability beyond $120 \mathrm{~h}$, benefitting from the structural merits including largely exposed active surface, unobstructed mass diffusion pathways, and improved charge transportation.

\section{Results and discussion}

$\mathrm{Co}_{0.6} \mathrm{Fe}_{0.4} \mathrm{P}$ nanoframes were prepared by a straightforward strategy containing three sequential steps including template growth, framework etching, and phosphorization. The detailed procedure and synthesis conditions are illustrated in Fig. 1 and detailed in the Experimental section (ESI $\dagger$ ). Samples etched with different amounts of urea prior to phosphorization are respectively denoted as $\mathrm{Co}_{0.6} \mathrm{Fe}_{0.4}-0, \mathrm{Co}_{0.6} \mathrm{Fe}_{0.4}-0.75, \mathrm{Co}_{0.6} \mathrm{Fe}_{0.4^{-}}$ 1.125 and $\mathrm{Co}_{0.6} \mathrm{Fe}_{0.4}-1.5$ according to the mass ratio of urea to the Co-Fe PBA template. After phosphorization, they are denoted as $\mathrm{Co}_{0.6} \mathrm{Fe}_{0.4} \mathrm{P}-0, \mathrm{Co}_{0.6} \mathrm{Fe}_{0.4} \mathrm{P}-0.75, \mathrm{Co}_{0.6} \mathrm{Fe}_{0.4} \mathrm{P}-1.125$ and $\mathrm{Co}_{0.6} \mathrm{Fe}_{0.4} \mathrm{P}-1.5$ accordingly. The $\mathrm{Co} / \mathrm{Fe}$ ratio in all samples was verified using Inductively Coupled Plasma-Atomic Emission Spectrometry (ICP-AES), unanimously showing a ratio of approximately $1.5: 1$, which reflects the feed ratio of the reactants (Table $\mathrm{S} 1 \dagger$ ). Fig. 2a presents the X-ray diffraction (XRD) spectra of the as-prepared $\mathrm{Co}_{0.6} \mathrm{Fe}_{0.4}-\mathrm{O}$ (Co-Fe PBA), $\mathrm{Co}_{0.6} \mathrm{Fe}_{0.4^{-}}$ 1.125 (before phosphorization), and $\mathrm{Co}_{0.6} \mathrm{Fe}_{0.4} \mathrm{P}-1.125$ (after phosphorization). The XRD spectra of Co-Fe PBAs with and without etching exhibit similar patterns with prominent peaks at $2 \theta=16.7^{\circ}, 24.1^{\circ}$ and $34.9^{\circ}$ that are assignable to the (200), (220) and (400) planes of Co-Fe PBAs, respectively, matching well with its standard profile of PDF \# 75-0039. Notably, while the Co-Fe PBA without etching displays broaden and skewed diffraction peaks, those of the etched samples appear sharper with a narrowed full width at half maximum (FWHM). This is likely due to the high temperature etching conditions that improve the crystallinity of PBAs. After phosphorization, the crystallinity of all samples drastically decreases, with a few



Fig. 1 Schematic illustration of the preparation of the nanoframes composed of $\mathrm{CO}_{0.6} \mathrm{Fe}_{0.4} \mathrm{P} N \mathrm{Ns}$ coated with the carbon matrix. (i) Self-assembly of $\mathrm{Co}-\mathrm{Fe}$ PBA; (ii) etching of the Co-Fe PBA to produce nanocages; (iii) phosphidation of the Co-Fe PBA nanocages to obtain subsequent $\mathrm{CO}_{0.6} \mathrm{Fe}_{0.4} \mathrm{P}$ NPs coated with the carbon matrix. 

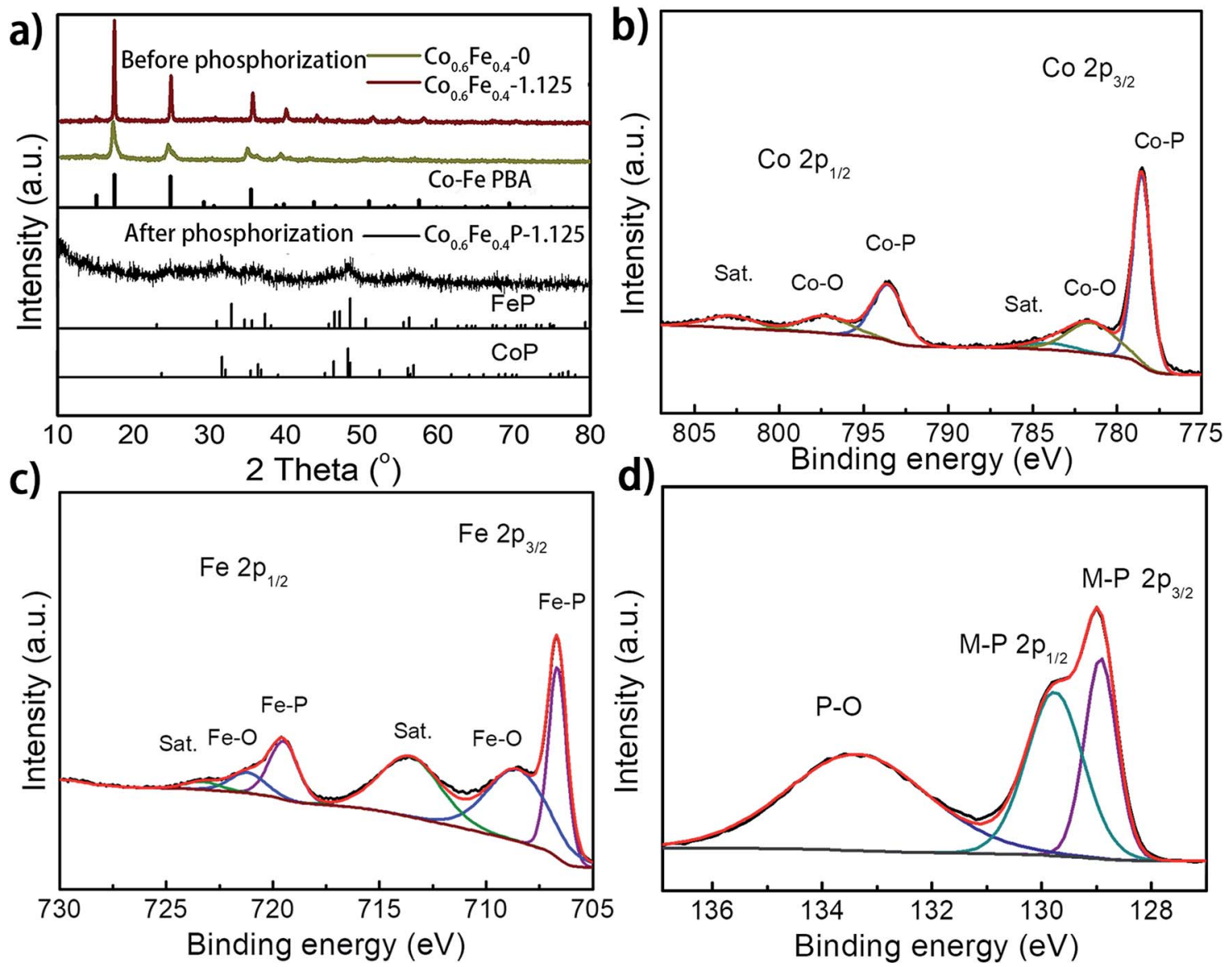

Fig. 2 (a) Powder XRD patterns of the $\mathrm{Co}_{0.6} \mathrm{Fe}_{0.4} \mathrm{PBA}$ before and after etching, and the $\mathrm{Co}_{0.6} \mathrm{Fe}_{0.4} \mathrm{P}-1.125$ after phosphorization; high-resolution XPS (b) Co 2p, (c) Fe 2p, (d) P 2p spectra of the $\mathrm{Co}_{0.6} \mathrm{Fe}_{0.4} \mathrm{P}-1.125$.

broad peaks distinguishable at $2 \theta=31.9^{\circ}, 36.5^{\circ}, 48.3^{\circ}$, and $56.8^{\circ}$, inferring a homogeneous solid solution of CoP (PDF \# 290497) and FeP (PDF \# 71-2262), both having similar crystallographic features to each other (Fig. 2a). ${ }^{39,43,48}$ This point of view was further corroborated by the observation of increased crystallinity with increasing phosphorization temperature (Fig. S1 and $\mathrm{S} 2 \dagger)$. The resemblance of XRD patterns of both CoP and FeP legitimizes the notation of the bimetal phosphides as $\mathrm{Co}_{0.6} \mathrm{Fe}_{0.4} \mathrm{P}$, instead of the $\mathrm{M}_{2} \mathrm{P}$ stoichiometry that was also observed previously for other TMPs. ${ }^{39}$

X-ray photoelectron spectroscopy (XPS) analysis further confirmed the successful phosphorization of the Co-Fe PBA nanoframes. The survey spectra of the $\mathrm{Co}_{0.6} \mathrm{Fe}_{0.4} \mathrm{P}-1.125$ reveal the presence of $\mathrm{Co}, \mathrm{Fe}, \mathrm{P}, \mathrm{C}, \mathrm{N}$ and $\mathrm{O}$ in the examined sample (Fig. S3a, ESI $\dagger$ ), in which the $\mathrm{O}$ element may originate from the absorbed oxygen species and superficial oxidation due to air contact. In the high-resolution XPS Co 2p spectrum (Fig. 2b), the binding energies (BE) located at $778.6 \mathrm{eV}$ and $793.5 \mathrm{eV}$ are respectively the spin-orbitals of Co $2 \mathrm{p}_{3 / 2}$ and $2 \mathrm{p}_{1 / 2}$ that can be assigned to Co-P. The peaks centered at $781.8 \mathrm{eV}$ and $797.8 \mathrm{eV}$ can be respectively attributed to the $2 \mathrm{p}_{3 / 2}$ and $2 \mathrm{p}_{1 / 2}$ spin-orbitals of cobalt in $\mathrm{Co}-\mathrm{O}$, indicating partial oxidation of cobalt at the surface in contact with oxygen in air. Satellite peaks located at 785.4 and $802.9 \mathrm{eV}$ are likely due to the shakeup excitation of the high-spin $\mathrm{Co}^{2+}$ ions. ${ }^{49-52}$ As for the high-resolution XPS spectra of Fe 2p (Fig. 2c), while the BE peaks at $706.7 \mathrm{eV}$ and $718.1 \mathrm{eV}$ are respectively assigned to the $2 \mathrm{p}_{3 / 2}$ and $2 \mathrm{p}_{1 / 2}$ spinorbitals of Fe-P, the peaks at $710.4 \mathrm{eV}$ and $723.7 \mathrm{eV}$ can be attributed to the oxidation of $\mathrm{Fe}$ on the surface as well. ${ }^{53}$ Correspondingly, the P species with the binding energy of 129.0 and $130.1 \mathrm{eV}$ are assigned to the $\mathrm{P} 2 \mathrm{p}_{1 / 2}$ and $\mathrm{P} 2 \mathrm{p}_{3 / 2}$ states of metal phosphides, ${ }^{\mathbf{5 4 5 5}}$ and the peaks at about $133.8 \mathrm{eV}$ represent the oxidized $\mathrm{P}$ species $(\mathrm{P}-\mathrm{O}, \mathrm{P}=\mathrm{O}$, etc.) due to air exposure (Fig. 2d). ${ }^{56-59}$ It is worthwhile to note that when compared to the metallic Fe, Co, and elemental $P$ species, the binding energies of Fe 2p and Co $2 \mathrm{p}$ observed here show apparently a positive shift and those of $\mathrm{P} 2 \mathrm{p}$ are negatively shifted, evidencing partial charge transfer between the metal and phosphorus atoms. In electrolysis, the positive metallic centers can act as the hydride acceptor whereas the negative $P$ centers can play the role of a proton acceptor. ${ }^{60,61}$ Furthermore, the positive BE shift of the Co and Fe 2p orbitals indicates the enhanced ability of electron transfer, whereas the negative shift of $\mathrm{P} 2 \mathrm{p}$ suggests higher potency for electron-donation, paving the way for the use of $\mathrm{Co}_{0.6} \mathrm{Fe}_{0.4} \mathrm{P}$ as a bifunctional catalyst for both the HER and OER. ${ }^{62}$ Furthermore, the high-resolution XPS N 1s spectrum can be deconvoluted into three sub-peaks, corresponding to the pyridinic- $\mathrm{N}(398.51 \mathrm{eV})$, pyrrolic- $\mathrm{N}(399.80 \mathrm{eV})$ and quaternary- $\mathrm{N}$ $(402.28 \mathrm{eV}$ ), respectively (Fig. S3b $\dagger$ ). The abundant pyridinic-N is reportedly beneficial to the electrocatalytic performance by 
offering an electron-rich local environment surrounding the metal centers. ${ }^{63}$

The Raman spectrum of the obtained $\mathrm{Co}_{0.6} \mathrm{Fe}_{0.4} \mathrm{P}$ nanoframes displays a D-band at $1338 \mathrm{~cm}^{-1}$ and G-band at $1580 \mathrm{~cm}^{-1}$, characteristic of the carbon matrix derived from MOF linkers (Fig. S3c $\dagger$ ). The G-band corresponds to the $\mathrm{E}_{2 \mathrm{~g}^{-}}$ vibration of graphitic carbon and the D-band arises from the defects within the carbon matrix. Specifically, for $\mathrm{Co}_{0.6} \mathrm{Fe}_{0.4} \mathrm{P}-$ 1.125 the intensity ratio of $I_{\mathrm{D}} / I_{\mathrm{G}}$ is 1.33 , suggesting a low degree of graphitization and the existence of a large amount of defects in the carbon matrix. ${ }^{64}$ The thermogravimetric analysis (TGA) curves of Co-Fe PBA (Fig. S3d $\dagger$ ) in air indicate that the MOF decomposition starts from $260{ }^{\circ} \mathrm{C}$ after the desorption of water, which is lower than the temperature of phosphorization. As for $\mathrm{Co}_{0.6} \mathrm{Fe}_{0.4} \mathrm{P}-1.125$, TGA in air shows that after the loss of ligand content the sample regains weight at higher temperature due to the oxidation of Co, Fe and P elements (Fig. S3e $\dagger$ ). The $\mathrm{N}_{2}$ adsorption-desorption measurements (Fig. S4 $\dagger$ ) indicate that etching with urea almost doubles the specific surface area for $\mathrm{Co}_{0.6} \mathrm{Fe}_{0.4}-1.125$ (vs. $\mathrm{Co}_{0.6} \mathrm{Fe}_{0.4}-0$ ), and the phosphorization treatment further promotes the specific surface area, resulting in a high specific surface area of $104.52 \mathrm{~m}^{2} \mathrm{~g}^{-1}$ and a total pore volume of $0.53 \mathrm{~cm}^{3} \mathrm{~g}^{-1}$ for $\mathrm{Co}_{0.6} \mathrm{Fe}_{0.4} \mathrm{P}-1.125$, which are amongst the highest reported for TMP nanostructures. ${ }^{65}$

The micro-morphology and ultrafine structure of Co-Fe PBA nanoframes before and after phosphorization were
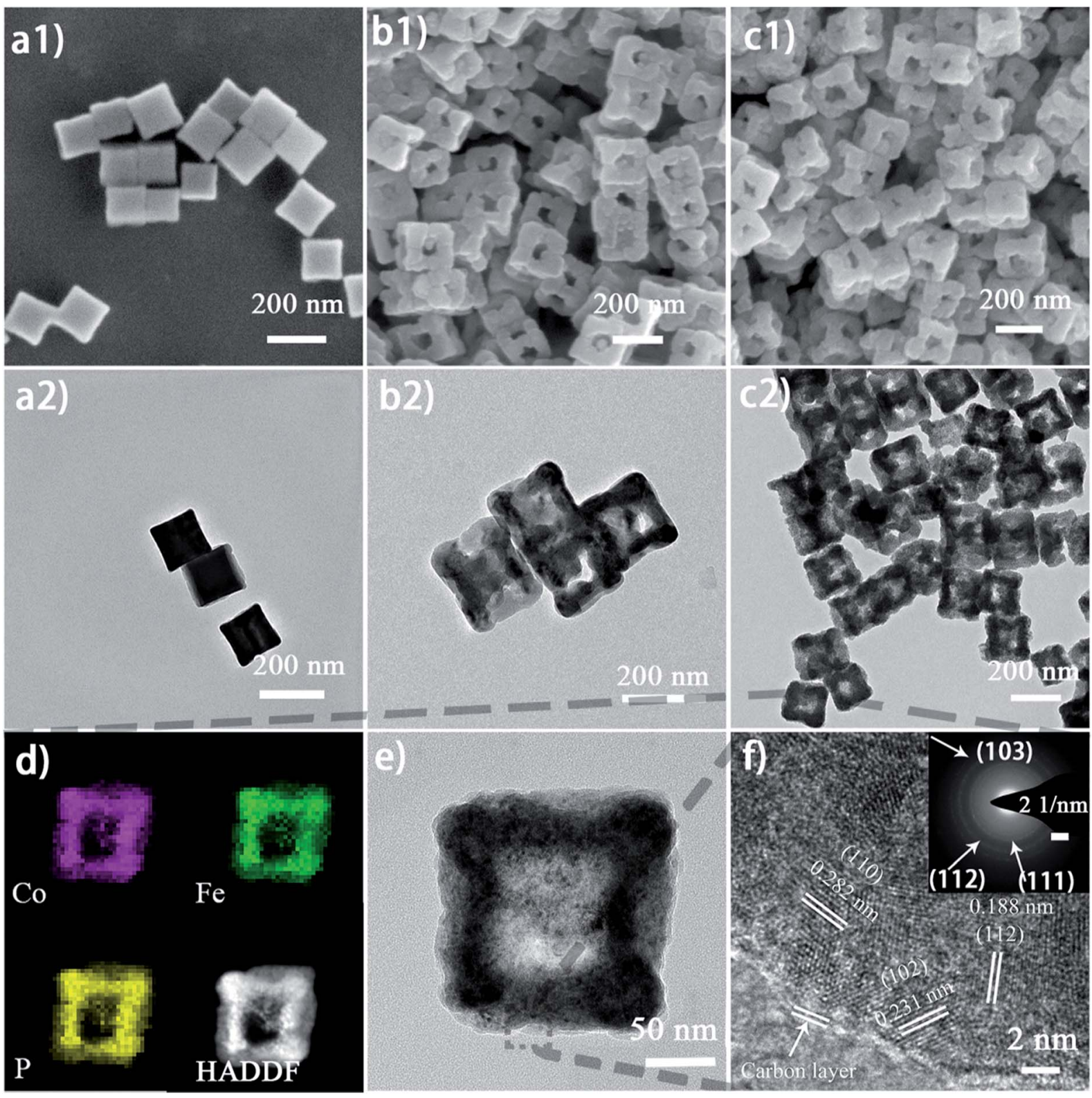

Fig. 3 (a1) and (a2) SEM and TEM images of the $\mathrm{CO}_{0.6} \mathrm{Fe}_{0.4}$ PBA nanocubes without etching; (b1) and (b2) $\mathrm{SEM}$ and TEM images of $\mathrm{CO}_{0.6} \mathrm{Fe}_{0.4}{ }^{-}$ 1.125 nanoframes before phosphorization; (c1) and (c2) SEM and TEM images of $\mathrm{CO}_{0.6} \mathrm{Fe}_{0.4} \mathrm{P}-1.125$ nanoframes after phosphorization; (d) elemental mapping images of an individual $\mathrm{Co}_{0.6} \mathrm{Fe}_{0.4} \mathrm{P}-1.125$ nanoframe showing the uniformly distributed $\mathrm{Co}, \mathrm{Fe}$, and $\mathrm{P}$ elements; (e) and (f) $\mathrm{HR}-\mathrm{TEM}$ and $\mathrm{SAD}$ images of $\mathrm{CO}_{0.6} \mathrm{Fe}_{0.4} \mathrm{P}-1.125$ showing polycrystalline lattice fringes. 
characterized using scanning electron microscopy (SEM) and high-resolution transmission electron microscopy (HR-TEM). The as-synthesized Co-Fe PBA presents highly uniform nanocubes with a smooth surface and an average size of $167 \pm 22 \mathrm{~nm}$ (Fig. 3a). After etching, carved nanoframes that inherit the shape and size of the Co-Fe PBA prototype were obtained, as a result of $\mathrm{NH}_{4}{ }^{+}$etching from the slowly decomposed urea and the different reaction and diffusion rates of $\mathrm{Co} / \mathrm{Fe}$ ions between the edge and face center of the Co-Fe PBA nanocubes (Fig. 3b and S5b†). In contrast, direct etching with ammonium leads to irregular and collapsed nanostructures because of the strong solvent polarity and fast reaction rate (Fig. S6†). ${ }^{66}$ Unlike previously reported etching methods using either the thermal heating alone or ammonia solutions, ${ }^{67-71}$ here urea serves as both structure-directing and etching agents. Due to the high surface energy and unsaturated coordination of metal ions at the edge and corner sites of $\mathrm{Co}_{0.6} \mathrm{Fe}_{0.4} \mathrm{PBA}$, urea molecules are preferably and more strongly coordinated to these places and therefore slow down their subsequent etching by the $\mathrm{NH}_{4}{ }^{+}$. By contrast, the $\mathrm{Co} / \mathrm{Fe}$ ions at the face center are more vulnerable to $\mathrm{NH}_{4}{ }^{+}$, resulting in nanocubes with concaved sides when a low etchant dosage was used (Fig. S7a and S7b $\dagger$ ), nanoframes when the proper amount of etchant was employed (Fig. 3b), and collapsed nanoframes when the etchant was overdosed (Fig. S7c †). Additionally, when $\mathrm{Co}_{0.6} \mathrm{Fe}_{0.4}$ PBA nanocubes were subjected to the same heat treatment without adding urea (Fig. S5a †), no particle etching was visualized, indicating that with the reactant precursors and reaction conditions employed in this study, the thermal treatment alone was not capable of restructuring the PBA nanoparticles.

After phosphorization, the structure of nanoframes remains intact, with a slightly roughened surface (Fig. $3 \mathrm{c}$ and S5c广). To further investigate the lattice feature of the $\mathrm{Co}_{0.6} \mathrm{Fe}_{0.4} \mathrm{P}$ nanoframes and the surrounding environment of the metal phosphides, high-resolution TEM (HR-TEM) and energy dispersive X-ray spectroscopy (EDX) analyses were carried out, showing that $\mathrm{Co}_{0.6} \mathrm{Fe}_{0.4} \mathrm{P}$ nanoparticles are homogeneously embedded in the amorphous carbon matrix. Both HR-TEM images (Fig. 3f and S8 $\mathrm{a} \dagger$ ) and XRD Debye-Scherrer calculations (Fig. S8b $\dagger$ ) suggest that the average size of $\mathrm{Co}_{0.6} \mathrm{Fe}_{0.4} \mathrm{P}$ nanoparticles is about only $3.5 \mathrm{~nm}$, thanks to the low annealing temperature and the slow Ostwald ripening. Clear lattice fringes with interplanar distances of $0.282,0.231$ and $0.188 \mathrm{~nm}$, respectively, corresponding to the (110), (102), and (112) planes of $\mathrm{Co}_{0.6} \mathrm{Fe}_{0.4} \mathrm{P}$, are measured in the HR-TEM images, further supporting that the bimetal phosphide is a solid solution of CoP and FeP, rather than a simple mix of phases. This argument is further verified by the selected area (electron) diffraction (SAD) image (Fig. 3f, inset) showing the polycrystalline nature with three major diffraction planes and the EDX mapping images (Fig. 3d) showing the uniform distribution of $\mathrm{Co}$, Fe and $\mathrm{P}$ in the nanoframes. In addition, the EDX elemental analysis (Table $\mathrm{S} 1 \dagger)$ further confirms that the atomic ratio of $\mathrm{Co}: \mathrm{Fe}$ is approximately $1.5: 1$, in line with the theoretical content $(6: 4)$ and ICP measurements. All the above microscopic and spectroscopic characterizations unambiguously show that the lowtemperature phosphorization process enables transformation of the bimetallic PBA precursors into homogeneous bimetallic phosphides without damaging the framework and morphology, providing a large specific surface area and porous structure of the catalyst with abundant active sites. ${ }^{72,73}$

The HER performance of the as-prepared $\mathrm{Co}_{0.6} \mathrm{Fe}_{0.4} \mathrm{P}$ nanoframes was investigated using a standard three-electrode system in $1.0 \mathrm{M} \mathrm{KOH}$ electrolyte. To minimize the capacitive current, the scan rate was set to $5 \mathrm{mV} \mathrm{s}^{-1}$ for acquiring all the linear sweep voltammetry (LSV) curves without iR compensation (Fig. 4a). Among all $\mathrm{Co}_{0.6} \mathrm{Fe}_{0.4} \mathrm{P}$ samples, $\mathrm{Co}_{0.6} \mathrm{Fe}_{0.4} \mathrm{P}-1.125$ exhibits an overpotential of $133 \mathrm{mV}$ at a current density of 10 $\mathrm{mA} \mathrm{cm}{ }^{-2}$, which is much smaller than those of $\mathrm{Co}_{0.6} \mathrm{Fe}_{0.4} \mathrm{P}-$ 0 (164 mV), $\mathrm{Co}_{0.6} \mathrm{Fe}_{0.4} \mathrm{P}-0.75(156 \mathrm{mV})$ and $\mathrm{Co}_{0.6} \mathrm{Fe}_{0.4} \mathrm{P}-1.5$ (162 $\mathrm{mV})$. Moreover, to reach a current density of $50 \mathrm{~mA} \mathrm{~cm}{ }^{-2}$, the HER overpotential of the above samples are, respectively, $211 \mathrm{mV}\left(\mathrm{Co}_{0.6} \mathrm{Fe}_{0.4} \mathrm{P}-1.125\right), 262 \mathrm{mV}\left(\mathrm{Co}_{0.6} \mathrm{Fe}_{0.4} \mathrm{P}-0\right), 249 \mathrm{mV}$ $\left(\mathrm{Co}_{0.6} \mathrm{Fe}_{0.4} \mathrm{P}-0.75\right)$, and $259 \mathrm{mV}\left(\mathrm{Co}_{0.6} \mathrm{Fe}_{0.4} \mathrm{P}-1.5\right)$. Obviously, upon etching with urea the carved $\mathrm{Co}_{0.6} \mathrm{Fe}_{0.4} \mathrm{P}$ nanoframes demonstrate better HER activities than the $\mathrm{Co}_{0.6} \mathrm{Fe}_{0.4} \mathrm{P}$ nanocubes $\left(\mathrm{Co}_{0.6} \mathrm{Fe}_{0.4} \mathrm{P}-0\right)$, thanks to the open $3 \mathrm{D}$ frameworks. Notably, the best HER activity obtained using $\mathrm{Co}_{0.6} \mathrm{Fe}_{0.4} \mathrm{P}-1.125$ is only $102 \mathrm{mV}$ away from the overpotential required by $20 \% \mathrm{Pt} /$ $\mathrm{C}$ for achieving the current density of $50 \mathrm{~mA} \mathrm{~cm}{ }^{-2}$. To further comprehend the HER kinetics, Tafel slopes were examined by linearly fitting the transformed polarization curves using the
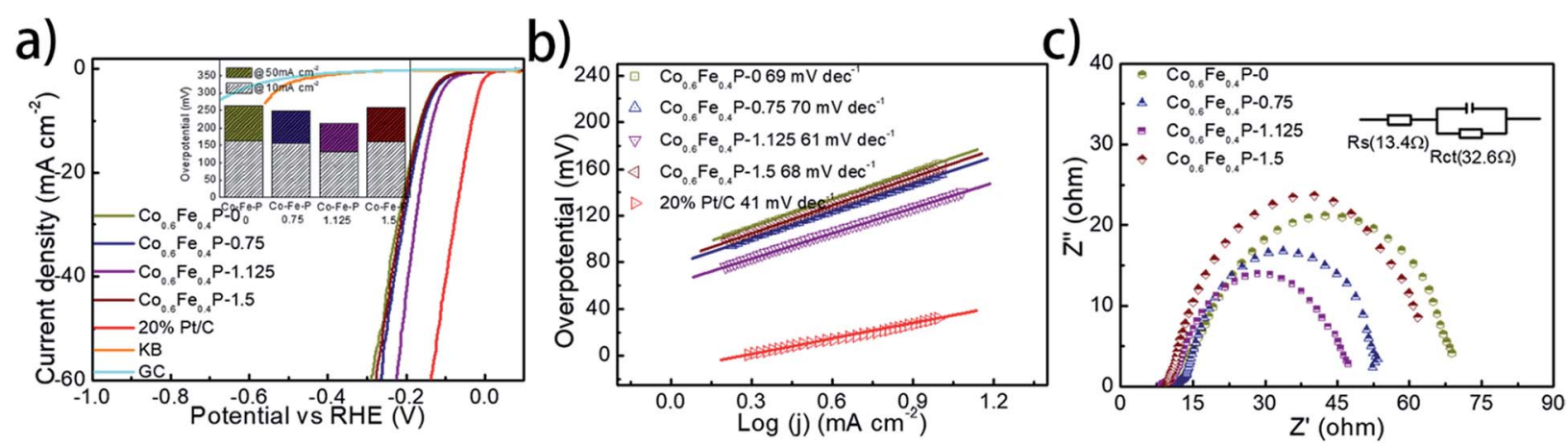

Fig. 4 (a) Polarization curves of $\mathrm{CO}_{0.6} \mathrm{Fe}_{0.4} \mathrm{P}$ and control samples for the $\mathrm{HER}$ in $1.0 \mathrm{M} \mathrm{KOH}$ (inset: the column diagram of $\mathrm{HER}$ activities for all

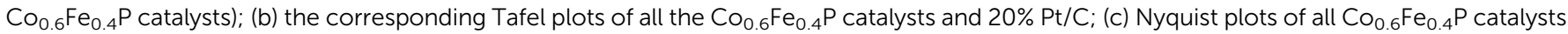
at $-0.15 \mathrm{~V}$ over the frequency range from 100000 to $0.01 \mathrm{~Hz}$. 
Tafel equation $(\eta=b \log j+a$, where $\eta$ is the overpotential, $b$ is the Tafel slope, $j$ is the current density, and $a$ is a constant that equals the onset overpotential). Generally speaking, the Tafel slope can be regarded as the required overpotential for augmenting the exchange current by ten times, and therefore the lower the slope, the higher the reaction kinetics. Fig. $4 \mathrm{~b}$ shows the linear Tafel slopes of all $\mathrm{Co}_{0.6} \mathrm{Fe}_{0.4} \mathrm{P}$ catalysts in comparison to the $\mathrm{Pt} / \mathrm{C}$ benchmark. As expected, in the alkaline electrolyte the $20 \% \mathrm{Pt} / \mathrm{C}$ exhibits the lowest Tafel slope of only $41 \mathrm{mV}$ $\mathrm{dec}^{-1} \cdot \mathrm{Co}_{0.6} \mathrm{Fe}_{0.4} \mathrm{P}-1.125$ presents a Tafel slope of $61 \mathrm{mV} \mathrm{dec}^{-1}$, lower than those of all other $\mathrm{Co}_{0.6} \mathrm{Fe}_{0.4} \mathrm{P}$ nanoframes, suggesting a rapid HER rate and a Volmer-Heyrovsky mechanism with the electrochemical desorption of hydrogen as the rate-limiting step.

The electrochemically active surface area (ECSA) of $\mathrm{Co}_{0.6} \mathrm{Fe}_{0.4} \mathrm{P}$ nanoframes was estimated by calculating the double-layer capacitance from cyclic voltammetry $(\mathrm{CV})$ curves at different scan rates in the voltage range between 0.22 and $0.42 \mathrm{~V}$ (vs. RHE) without any redox processes (Fig. S9†). A linear correlation can be observed when the current density at $0.32 \mathrm{~V}$ is plotted against the scan rate for all samples. It is clear that $\mathrm{Co}_{0.6} \mathrm{Fe}_{0.4} \mathrm{P}-1.125$ possesses the largest $C_{\mathrm{dl}}\left(22.05 \mathrm{mF} \mathrm{cm}{ }^{-2}\right)$ amongst all $\mathrm{Co}_{0.6} \mathrm{Fe}_{0.4} \mathrm{P}$ samples, indicative of the highest surface area and exposure of active sites, ${ }^{74}$ which is in good agreement with the former BET measurements. In addition to the ECSA, the charge transfer resistance $\left(R_{\mathrm{ct}}\right)$ at the electrode/ electrolyte interface is another crucial parameter that reflects the kinetics of the redox reactions. The lower value of $R_{\mathrm{ct}}$ suggests the enhanced charge transfer rate between the electrocatalyst and redox species, and thus the improved HER activity. Among all $\mathrm{Co}_{0.6} \mathrm{Fe}_{0.4} \mathrm{P}$ samples, $\mathrm{Co}_{0.6} \mathrm{Fe}_{0.4} \mathrm{P}-1.125$ has the lowest $R_{\mathrm{ct}}$ of $32.6 \Omega$ (Fig. 4c), revealing a much faster electron-transfer rate than its counterpart nanocubes $\left(\mathrm{Co}_{0.6} \mathrm{Fe}_{0.4} \mathrm{P}-0\right)$. Consequently, both the enlarged ECSA and lowered $R_{\text {ct }}$ should help explain the enhanced HER activity of the $\mathrm{Co}_{0.6} \mathrm{Fe}_{0.4} \mathrm{P}-1.125$ nanoframes.

To further study the $\mathrm{pH}$ versatility of the $\mathrm{Co}_{0.6} \mathrm{Fe}_{0.4} \mathrm{P}$ nanoframes regarding their HER activities, neutral and acidic electrolytes were also examined. In 1.0 M phosphate buffered saline (PBS) $(\mathrm{pH}=7.0)$, all catalysts including Pt/C exhibit inferior
HER activities (Fig. S10a1 and S10a2 $\dagger$ ) in comparison to those under alkaline conditions. To reach a current density of $10 \mathrm{~mA}$ $\mathrm{cm}^{-2}$, the $20 \% \mathrm{Pt} / \mathrm{C}$ needs an overpotential of $98 \mathrm{mV}$, whereas $\mathrm{Co}_{0.6} \mathrm{Fe}_{0.4} \mathrm{P}-1.125$ requires $140 \mathrm{mV}$. However, at a higher current density of $30 \mathrm{~mA} \mathrm{~cm}{ }^{-2}$, the HER overpotential of $\mathrm{Co}_{0.6} \mathrm{Fe}_{0.4} \mathrm{P}$ $1.125(250 \mathrm{mV})$ is even lower than that of $\mathrm{Pt} / \mathrm{C}(340 \mathrm{mV})$. In the acidic medium of $0.5 \mathrm{M} \mathrm{H}_{2} \mathrm{SO}_{4}$, the catalytic activities of all examined samples surpass those observed under both alkaline and neutral conditions, with $\mathrm{Co}_{0.6} \mathrm{Fe}_{0.4} \mathrm{P}-1.125$ exhibiting overpotentials of only 97 and $170 \mathrm{mV}$ to achieve the current densities of 10 and $50 \mathrm{~mA} \mathrm{~cm}^{-2}$, respectively (Fig. S10b1 and S10b2 $\dagger$ ). The high HER activities in the acidic medium are likely due to the readily available $\mathrm{H}^{+}$ions and thus facilitated proton adsorption. It is worth noting that the HER activities observed here on the $\mathrm{Co}_{0.6} \mathrm{Fe}_{0.4} \mathrm{P}$ nanoframes surpass those of the majority of the non-noble-metal based TMP catalysts reported to date. ${ }^{49,75}$

To facilitate high-efficiency overall water splitting, the OER is the other equally important half reaction as the HER but might be even more kinetically sluggish due to the multiple electron transfer. Fig. 5a shows the polarization curves of all $\mathrm{Co}_{0.6} \mathrm{Fe}_{0.4} \mathrm{P}$ samples obtained by LSV without any iR compensation in the alkaline electrolyte $(1.0 \mathrm{M} \mathrm{KOH}, \mathrm{pH}=14)$. Commercial $\mathrm{RuO}_{2}$ is used for benchmark comparison. Among all examined samples, $\mathrm{Co}_{0.6} \mathrm{Fe}_{0.4} \mathrm{P}-1.125$ shows the best OER activity with a required overpotential of only $298 \mathrm{mV}$ to reach a current density of $10 \mathrm{~mA}$ $\mathrm{cm}^{-2}$, even smaller than that of $\mathrm{RuO}_{2}(326 \mathrm{mV})$. The corresponding Tafel slope of $\mathrm{Co}_{0.6} \mathrm{Fe}_{0.4} \mathrm{P}-1.125$ for the OER is $48 \mathrm{mV}$ $\mathrm{dec}^{-1}$, also below that of $\mathrm{RuO}_{2}\left(62 \mathrm{mV} \mathrm{dec}^{-1}\right)$. By contrast, the overpotentials to reach a current density of $10 \mathrm{~mA} \mathrm{~cm}{ }^{-2}$ for $\mathrm{Co}_{0.6} \mathrm{Fe}_{0.4} \mathrm{P}-0, \mathrm{Co}_{0.6} \mathrm{Fe}_{0.4} \mathrm{P}-0.75$ and $\mathrm{Co}_{0.6} \mathrm{Fe}_{0.4} \mathrm{P}-1.5$ are 308, 301, and $304 \mathrm{mV}$, respectively, with the corresponding Tafel slopes of 53, 54, and $55 \mathrm{mV} \mathrm{dec}{ }^{-1}$. In addition, Nyquist plots (Fig. 5c) obtained at $1.53 \mathrm{~V}$ ( $v s$. RHE) reveal a dramatically decreased $R_{\mathrm{ct}}$ for $\mathrm{Co}_{0.6} \mathrm{Fe}_{0.4} \mathrm{P}-1.125$ (24.2 $\Omega$ ), much smaller than those of other $\mathrm{Co}_{0.6} \mathrm{Fe}_{0.4} \mathrm{P}$ samples under the same OER operating conditions. Such a good OER performance of $\mathrm{Co}_{0.6} \mathrm{Fe}_{0.4} \mathrm{P}-1.125$ can be attributed to the same reasons in terms of the open $3 \mathrm{D}$ frameworks (thus facilitating electrolyte infiltration and gas release) and higher electrochemically active surface used to explain its

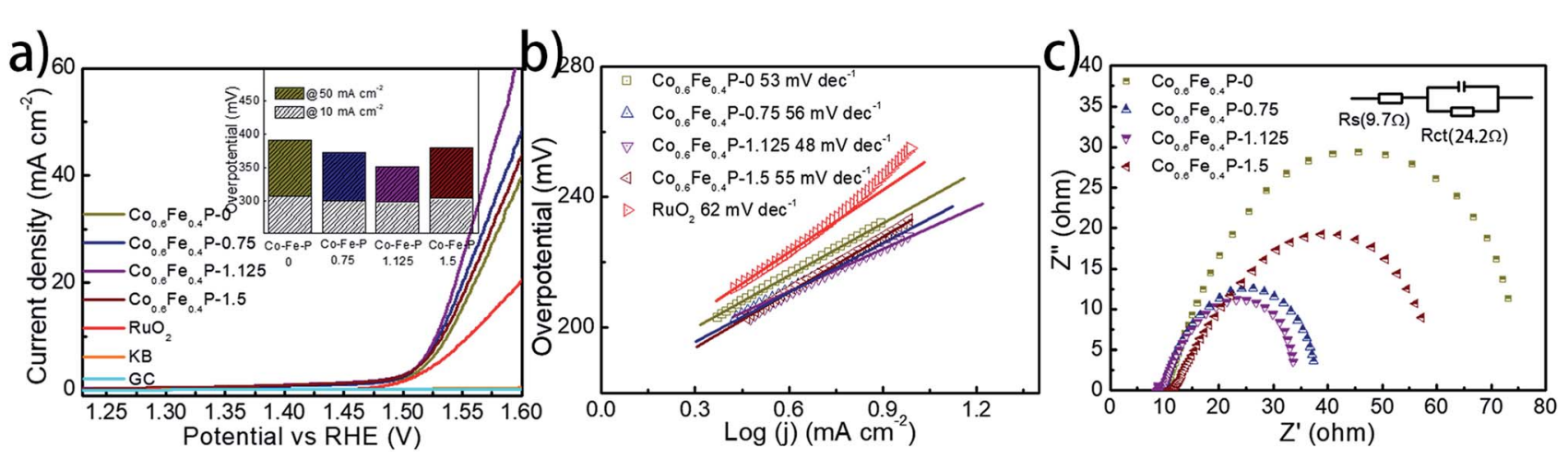

Fig. 5 (a) Polarization curves of $\mathrm{CO}_{0.6} \mathrm{Fe}_{0.4} \mathrm{P}$ and control samples for the $\mathrm{OER}$ in $1.0 \mathrm{M} \mathrm{KOH}$ (inset: the column diagram of OER activities for all $\mathrm{CO}_{0.6} \mathrm{Fe}_{0.4} \mathrm{P}$ catalysts); (b) the corresponding Tafel plots of all the $\mathrm{CO}_{0.6} \mathrm{Fe}_{0.4} \mathrm{P}$ catalysts and $\mathrm{RuO}_{2}$; (c) Nyquist plots of all $\mathrm{Co}_{0.6} \mathrm{Fe}_{0.4} \mathrm{P}$ catalysts at $-1.53 \mathrm{~V}$ over the frequency range from 100000 to $0.01 \mathrm{~Hz}$. 
excellent HER activity. However, when switched to a neutral or acidic electrolyte, the $\mathrm{Co}_{0.6} \mathrm{Fe}_{0.4} \mathrm{P}$ nanoframes exhibit less impressive OER activities, likely due to the dissolution of the in situ formed metal hydroxides/oxides, which will be discussed later.

To further explore the intrinsic catalytic activity and unveil the percentage of effective active sites of the catalyst, a slow scan of $\mathrm{CV}$ from 0.72 to $1.42 \mathrm{~V}$ was acquired (Fig S11 $\dagger$ ) for $\mathrm{Co}_{0.6} \mathrm{Fe}_{0.4} \mathrm{P}$ 1.125. The voltage range was so chosen for the complete oxidation of the catalytically active $\mathrm{Co}_{0.6} \mathrm{Fe}_{0.4} \mathrm{P}$ species. The prominent oxidation peak between $0.9 \mathrm{~V}$ and $1.4 \mathrm{~V}$ is presumably ascribed to the one-step oxidation of active $\mathrm{Co}_{0.6} \mathrm{Fe}_{0.4} \mathrm{P}$ to Co-Fe oxide/hydroxide through an 8-electron process (eqn (1)). By integrating the faradaic charge of the oxidation peak, we surmise that about $21.1 \%$ of the $\mathrm{Co}_{0.6} \mathrm{Fe}_{0.4} \mathrm{P}$ is effective and exploited in electrocatalysis, ${ }^{\mathbf{1 8}}$ again thanks to the open framework of $\mathrm{Co}_{0.6} \mathrm{Fe}_{0.4} \mathrm{P}-1.125$ (see the ESI $\dagger$ for calculation details). Therefore, the turnover frequency (TOF) can be estimated by quantifying the $\mathrm{H}_{2} / \mathrm{O}_{2}$ conversion per unit active site per unit time (Fig. S12 $\dagger$ ), whose logarithmic transformation shows a semi-linear increment with the applied overpotential. Specifically, at a current density of $10 \mathrm{~mA} \mathrm{~cm}{ }^{-2}$ the TOFs calculated for the HER and OER are 0.092 and $0.046 \mathrm{~s}^{-1}$, respectively, assuming the effective active sites work equally for both the HER and OER at a faradaic efficiency of $100 \%$.

$$
\begin{aligned}
& \mathrm{Co}_{0.6} \mathrm{Fe}_{0.4} \mathrm{P}+11 \mathrm{OH}^{-} \rightarrow \\
& \mathrm{Co}_{0.6} \mathrm{Fe}_{0.4} \mathrm{OOH}+\mathrm{PO}_{4}{ }^{3-}+8 \mathrm{e}^{-}+5 \mathrm{H}_{2} \mathrm{O}
\end{aligned}
$$

The remarkable HER and OER performance of the $\mathrm{Co}_{0.6} \mathrm{Fe}_{0.4} \mathrm{P}$ nanoframes in the alkaline electrolyte can be attributed to the open 3D frameworks, in addition to the high activity of bimetallic phosphides. ${ }^{76}$ On one hand, previous studies have shown that nanostructures of bimetallic phosphides exhibit superior water oxidation capability compared with their monometallic counterparts, owing to a synergic effect from the alloyed metals, as well as the increased density of states (DOS) at the Fermi level. ${ }^{77-79}$ This is further corroborated by our control studies on comparing the CoP, FeP and $\mathrm{Co}_{0.6} \mathrm{Fe}_{0.4} \mathrm{P}$ nanostructures (Fig. S13 and S14 $\dagger$ ). The thus optimized electronic structure of the electrocatalysts further enables more charge carriers to participate in the catalytic reactions, and allows optimizing the free energies of the reaction intermediates such as $\Delta G\left(\mathrm{H}^{*}\right)$ and $\Delta G\left(\mathrm{HO}^{*}\right)$, which are fundamental to their adsorption and desorption kinetics. ${ }^{\mathbf{8 0 , 8 1}}$ On the other hand, the open 3D frameworks not only endow $\mathrm{Co}_{0.6} \mathrm{Fe}_{0.4} \mathrm{P}$ nanostructures with a higher electrochemically active surface area and thus promote the charge transfer among reaction species, but also effectively facilitate the electrolyte infiltration and release of the evolved gas bubbles by providing unobstructed mass diffusion pathways. Moreover, the $\mathrm{Co}_{0.6} \mathrm{Fe}_{0.4} \mathrm{P}$ nanoparticles are embedded in the nitrogen-doped carbon shell derived from the decomposition of the cyanide ligands, which should help maintain good conductivity and stabilize the nanoparticles by keeping them from aggregation.

With both remarkable HER and OER performances demonstrated above, a two-electrode cell using $\mathrm{Co}_{0.6} \mathrm{Fe}_{0.4} \mathrm{P}-1.125$ as a bifunctional catalyst for both the anode and cathode was constructed in the alkaline electrolyte of $1.0 \mathrm{M} \mathrm{KOH}$ for overall water splitting. For comparison, an electrolyzer with $\mathrm{RuO}_{2}$ as the anode and $\mathrm{Pt} / \mathrm{C}$ as the cathode was also inspected. All catalysts were coated onto a $5 \times 5 \mathrm{~mm}^{2}$ nickel foam (NF) with

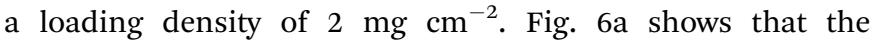
$\mathrm{Co}_{0.6} \mathrm{Fe}_{0.4} \mathrm{P}-1.125$ couple is able to deliver the overall water splitting with an exchange current density of $10 \mathrm{~mA} \mathrm{~cm} \mathrm{~cm}^{-2}$ at a cell voltage of $1.57 \mathrm{~V}$, slightly lower than that of the simple addition of overpotentials from the HER (133 mV) and OER (298 $\mathrm{mV}$ ). This is likely due to the larger specific surface area and better current-collecting ability of NF when compared to glassy carbon. The $1.57 \mathrm{~V}$ cell voltage is only $0.05 \mathrm{~V}$ higher than that of the $\mathrm{Pt} / \mathrm{C} \| \mathrm{RuO}_{2}$ couple $\left(1.52 \mathrm{~V}\right.$ @ $10 \mathrm{~mA} \mathrm{~cm}{ }^{-2}$ ), and surpasses those of the majority of bifunctional electrocatalysts reported for overall water splitting (Table S2 $\dagger$ ).

Durability and stability are vital criteria to assess electrocatalysts for practical applications. Herein, the durability of the $\mathrm{Co}_{0.6} \mathrm{Fe}_{0.4} \mathrm{P}-1.125$ couple was evaluated through successive $\mathrm{CV}$


Fig. 6 (a) The overall water splitting performance of the $\mathrm{CO}_{0.6} \mathrm{Fe}_{0.4} \mathrm{P}-1.125$ and $\mathrm{Pt} / \mathrm{C} \| \mathrm{RuO}_{2}$ couple in $1.0 \mathrm{M} \mathrm{KOH}$ (inset: photo of the overall water splitting reaction in a two-electrode configuration); (b) the catalytic stability of the $\mathrm{Co}_{0.6} \mathrm{Fe}_{0.4} \mathrm{P}-1.125$ for overall water splitting in $1.0 \mathrm{M}$ KOH (inset: the durability of $\mathrm{CO}_{0.6} \mathrm{Fe}_{0.4} \mathrm{P}-1.125$ for the HER and OER after 1000 and $5000 \mathrm{CV}$ cycles). 
scanning for 5000 continuous cycles. For the HER, the scan potential range was set from $0.10 \mathrm{~V}$ to $-0.25 \mathrm{~V}$ with a rate of $100 \mathrm{mV} \mathrm{s}^{-1}$, whereas for the OER, the scan range was from 1.20 to $1.65 \mathrm{~V}$ with the same scan rate. At the end of the $\mathrm{CV}$ measurements, both HER and OER polarization curves were acquired, showing negligible change in the overpotential and current density (insets in Fig. 6b). As for the electrochemical stability, a prolonged chronoamperometric test was conducted at a cell voltage of $1.65 \mathrm{~V}$, resulting in an exchange current density of $26.11 \mathrm{~mA} \mathrm{~cm}^{-2}$. After $120 \mathrm{~h}$ of extensive testing, the current density dropped only about 7.6\%, exhibiting excellent long-term stability (Fig. 6b). Such outstanding performance of $\mathrm{Co}_{0.6} \mathrm{Fe}_{0.4} \mathrm{P}-1.125$ endorses its promising application for efficient overall water splitting.

To further examine whether there are any morphological and compositional changes to the catalyst after the prolonged water splitting reaction, XRD, SEM-EDX, TEM, and XPS analyses were performed, with special attention being paid to the role and fate of the phosphorus element throughout the electrolytic process. Both SEM and TEM images show no morphological changes for $\mathrm{Co}_{0.6} \mathrm{Fe}_{0.4} \mathrm{P}-1.125$ on both the cathode and anode sides after the prolonged electrocatalytic reaction (Fig. S15 $\dagger$ ). EDX analysis (Fig. S16 $\dagger$ ), however, reveals that the loss of $\mathrm{P}$ and increase of $\mathrm{O}$ species after both the HER and OER. Specifically, for the $\mathrm{P}$ element, the atomic ratio drops from $32 \%$ in the pristine
$\mathrm{Co}_{0.6} \mathrm{Fe}_{0.4} \mathrm{P}-1.125$ sample to $16 \%$ and $1 \%$ in the post-HER and post-OER samples, respectively. In contrast, the atomic ratio of O increases from $17 \%$ to $35 \%$ and $46 \%$ for the pristine, postHER and post-OER samples, respectively. This elemental change was further confirmed by the XPS analysis (Fig. 7a-c, for more detailed peak analysis see Fig. S17†). In the high-resolution XPS spectra of Co 2p, Fe 2p and P 2p spin-orbitals, all peaks associated with the metal phosphides decrease in intensity evidently after the HER, and almost completely disappear after the OER. Instead, both $\mathrm{Co}-\mathrm{O}$ and $\mathrm{Fe}-\mathrm{O}$ species increase after electrolysis. As for the $\mathrm{P}-\mathrm{O}$ species, the highest intensity is observed on the pristine $\mathrm{Co}_{0.6} \mathrm{Fe}_{0.4} \mathrm{P}-1.125$ sample, followed sequentially by the post-HER and post-OER samples. This is because at the high electric potential under OER conditions, almost all the active $\mathrm{P}$ species will be converted to $\mathrm{PO}_{4}{ }^{3-}$ and dissolved into the electrolyte (eqn (1)), and even at the HER potential there is still a partial oxidation of the surface $\mathrm{P}$ atoms (see the $\mathrm{ESI}_{\dagger} \dagger$ for possible phosphorus-involving reaction in the HER process). These observations suggest while partially oxidized $\mathrm{Co}_{0.6} \mathrm{Fe}_{0.4} \mathrm{P}$ is still HER active, CoFe metal oxides/ hydroxides are the catalytic OER active sites formed in situ. ${ }^{31,82}$ As a result, in combination with the above CV study on effective active sites, these post-electrolysis characterizations unequivocally reveal the fate of phosphorus from the TMP catalysts in both the HER and OER sides of overall water splitting.

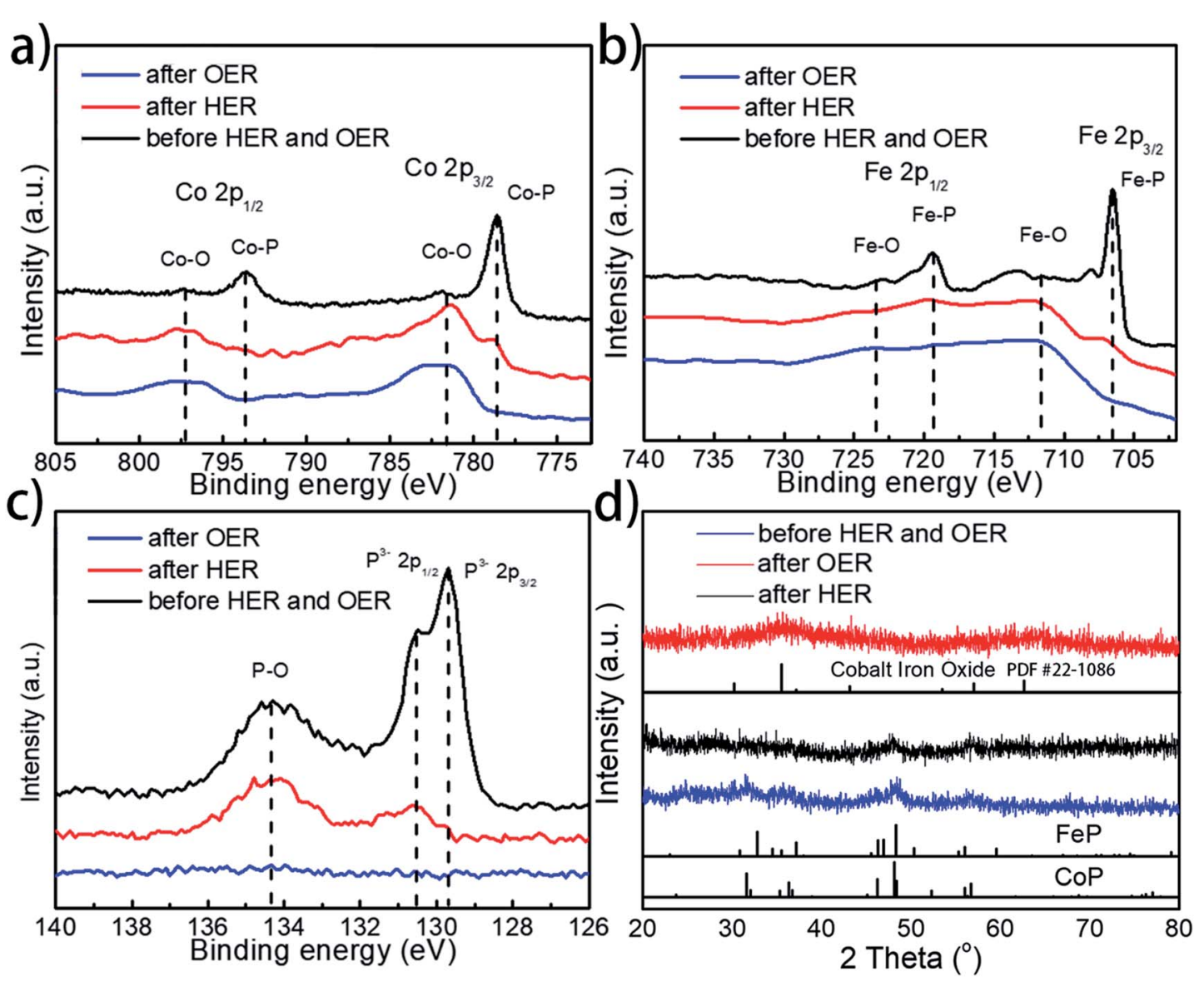

Fig. 7 High-resolution (a) Co 2p, (b) Fe 2p, and (c) P 2p XPS spectra of the as-prepared, post-HER and post-OER CO${ }_{0.6} \mathrm{Fe}_{0.4} \mathrm{P}-1.125$ catalysts; (d) XRD patterns of the as-prepared, post-HER and post-OER $\mathrm{CO}_{0.6} \mathrm{Fe}_{0.4} \mathrm{P}-1.125$ catalysts. 
Furthermore, XRD analysis on the post-electrolysis samples shows that $\mathrm{Co}_{0.6} \mathrm{Fe}_{0.4} \mathrm{P}-1.125$ exhibits a subtle change of the crystalline structure after the HER, but more seemingly oxide features after the OER (Fig. 7d) (Co-Fe oxide PDF \# 22-1086). This, again, suggests that the $\mathrm{Co}_{0.6} \mathrm{Fe}_{0.4} \mathrm{P}$ nanoparticles are partially oxidized on the surface under the HER conditions but more severely oxidized in the OER process, resulting in mostly amorphous metal oxides/hydroxides. Lastly, to further interrogate if the metal phosphides are indeed contributing to the outstanding catalytic performance observed, we annealed the sample $\mathrm{Co}_{0.6} \mathrm{Fe}_{0.4}-1.125$ in air at $300{ }^{\circ} \mathrm{C}$ and inspected both the HER and OER activities of the obtained nanoframes of Co-Fe oxides (Fig. S18 $\dagger$ ). Much inferior electrocatalytic activities with the overpotentials of 373 and $382 \mathrm{mV}$ at a current density of 10 $\mathrm{mA} \mathrm{cm}^{-2}$ respectively for the HER and OER were witnessed, indicating that the nanostructures of TMPs, although easily oxidized in situ, are crucial for their high water splitting performance.

\section{Conclusions}

In summary, we have demonstrated a facile route to prepare open 3D frameworks of Co-Fe bimetal phosphides as a superior catalyst for electrochemical water splitting. The structural and compositional advantages inherited from the Co-Fe PBA precursor account for the enhanced catalytic activities of the obtained nanoframes in both the HER and OER. Impressively, for the HER the $\mathrm{Co}_{0.6} \mathrm{Fe}_{0.4} \mathrm{P}-1.125$ nanoframes only require an overpotential of $97 \mathrm{mV}$ to achieve a $10 \mathrm{~mA} \mathrm{~cm}{ }^{-2}$ current density in $0.5 \mathrm{M} \mathrm{H}_{2} \mathrm{SO}_{4}$ and $133 \mathrm{mV}$ for $10 \mathrm{~mA} \mathrm{~cm}^{-2}$ in $1.0 \mathrm{M} \mathrm{KOH}$. For the OER, the required overpotential to reach $10 \mathrm{~mA} \mathrm{~cm}{ }^{-2}$ in the alkaline medium is only $297 \mathrm{mV}$. An electrolyzer employing the $\mathrm{Co}_{0.6} \mathrm{Fe}_{0.4} \mathrm{P}-1.125$ nanoframes as a bifunctional catalyst for both the cathode and anode delivered a current density of $10 \mathrm{~mA}$ $\mathrm{cm}^{-2}$ at a cell voltage of $1.57 \mathrm{~V}$ with extended stability beyond $120 \mathrm{~h}$, which is very close to those of integrated $\mathrm{Pt} / \mathrm{C}$ and $\mathrm{RuO}_{2}$ counterparts. This outstanding performance is attributed to the enhanced electrochemically active surface area, and the promoted mass diffusion and charge transportation, thanks to the open 3D framework of the TMP nanostructures. Further indepth activity analysis and post-electrolysis characterization revealed that while partially oxidized $\mathrm{Co}_{0.6} \mathrm{Fe}_{0.4} \mathrm{P}$ species are HER active, CoFe metal oxides/hydroxides are the catalytic OER active sites formed in situ. Through the carving of nanostructures for obtaining open 3D frameworks, this study demonstrates an effective tactic to promote both the HER and OER performance of bimetal phosphides towards efficient overall water splitting.

\section{Conflicts of interest}

There are no conflicts to declare.

\section{Acknowledgements}

This work was supported by the National Natural Science Foundation of China (No. 21701118), Natural Science
Foundation of Jiangsu Province (No. BK20161209 and No. BK20160323) and Key Technology Initiative of Suzhou Municipal Science and Technology Bureau (SYG201748). We also extend our sincere appreciation to the support by Suzhou Key Laboratory for Advanced Carbon Materials and Wearable Energy Technologies, Suzhou 215006, China.

\section{References}

1 J. A. Turner, Science, 2004, 305, 972.

2 H. B. Gray, Nat. Chem., 2009, 1, 7.

3 T. R. Cook, D. K. Dogutan, S. Y. Reece, Y. Surendranath, T. S. Teets and D. G. Nocera, Chem. Rev., 2010, 110, 64746502.

4 M. G. Walter, E. L. Warren, J. R. McKone, S. W. Boettcher, Q. Mi, E. A. Santori and N. S. Lewis, Chem. Rev., 2010, 110, 6446-6473.

5 C. G. Morales-Guio, L. A. Stern and X. Hu, Chem. Soc. Rev., 2014, 43, 6555-6569.

6 L. Han, S. Dong and E. Wang, Adv. Mater., 2016, 28, 92669291.

7 W. Zhang, W. Lai and R. Cao, Chem. Rev., 2017, 117, 37173797.

8 H. Su, H. H. Wang, B. Zhang, K. X. Wang, X. H. Li and J. S. Chen, Nano Energy, 2016, 22, 79-86.

9 H. Sun, Y. Lian, C. Yang, L. Xiong, P. Qi, Q. Mu, X. Zhao, J. Guo, Z. Deng and Y. Peng, Energy Environ. Sci., 2018, 11, 2363-2371.

10 Y. Xu, S. L. Yin, C. J. Li, K. Deng, H. R. Xue, X. N. Li, H. J. Wang and L. Wang, J. Mater. Chem. A, 2018, 6, 13761381.

11 F. Qin, Z. H. Zhao, M. K. Alam, Y. Z. Ni, F. Robles-Hernandez, L. Yu, S. Chen, Z. F. Ren, Z. M. Wang and J. M. Bao, ACS Energy Lett., 2018, 3, 546-554.

12 H. Jin, J. Wang, D. Su, Z. Wei, Z. Pang and Y. Wang, J. Am. Chem. Soc., 2015, 137, 2688-2694.

13 Z. Wu, J. Wang, L. Han, R. Lin, H. Liu, H. L. Xin and D. Wang, Nanoscale, 2016, 8, 4681-4687.

14 Z. Chen, Y. Ha, Y. Liu, H. Wang, H. Yang, H. Xu, Y. Li and R. Wu, ACS Appl. Mater. Interfaces, 2018, 10, 7134-7144.

15 H. Hu, L. Han, M. Z. Yu, Z. Wang and D. Lou, Energy Environ. Sci., 2015, 9, 107-111.

16 X. Shi, M. Fujitsuka, S. Kim and T. Majima, Small, 2018, 14, e1703277.

17 X. Fan, Z. Peng, R. Ye, H. Zhou and X. Guo, ACS Nano, 2015, 9, 7407-7418.

18 Y. Liu, G. Yu, G. D. Li, Y. Sun, T. Asefa, W. Chen and X. Zou, Angew. Chem., Int. Ed., 2015, 54, 10752-10757.

19 Y. Huang, Q. Gong, X. Song, K. Feng, K. Nie, F. Zhao, Y. Wang, M. Zeng, J. Zhong and Y. Li, ACS Nano, 2016, 10, 11337-11343.

20 X. J. Yang, X. J. Feng, H. Q. Tan, H. Y. Zang, X. L. Wang, Y. H. Wang, E. B. Wang and Y. G. Li, J. Mater. Chem. A, 2016, 4, 3947-3954.

21 J. Luo, J. H. Im, M. T. Mayer, M. Schreier, M. K. Nazeeruddin, N. G. Park, S. D. Tilley, H. J. Fan and M. Gratzel, Science, 2014, 345, 1593-1596. 
22 G. Chen, T. Wang, J. Zhang, P. Liu, H. Sun, X. Zhuang, M. Chen and X. Feng, Adv. Mater., 2018, 30, 1706279.

23 L. Wang, Q. Zhou, Z. Pu, Q. Zhang, X. Mu, H. Jing, S. Liu, C. Chen and S. Mu, Nano Energy, 2018, 53, 270-276.

24 S. H. Bae, J. E. Kim, H. Randriamahazaka, S. Y. Moon, J. Y. Park and I. K. Oh, Adv. Energy Mater., 2017, 7, 1601492.

25 M. Ledendecker, S. Krick Calderon, C. Papp, H. P. Steinruck, M. Antonietti and M. Shalom, Angew. Chem., Int. Ed., 2015, 54, 12361-12365.

26 X. Xiao, L. Tao, M. Li, X. Lv, D. Huang, X. Jiang, H. Pan, M. Wang and Y. Shen, Chem. Sci., 2018, 9, 1970-1975.

27 S. W. Li, Y. C. Wang, S. J. Peng, L. J. Zhang, A. M. Al-Enizi, H. Zhang, X. H. Sun and G. F. Zheng, Adv. Energy Mater., 2016, 6, 1501661.

28 D. Y. Chung, S. W. Jun, G. Yoon, H. Kim, J. M. Yoo, K. S. Lee, T. Kim, H. Shin, A. K. Sinha, S. G. Kwon, K. Kang, T. Hyeon and Y. E. Sung, J. Am. Chem. Soc., 2017, 139, 6669-6674.

29 F. Yu, H. Q. Zhou, Y. F. Huang, J. Y. Sun, F. Qin, J. M. Bao, W. A. Goddardiii, S. Chen and Z. F. Ren, Nat. Commun., 2018, 9, 2551.

30 Z. Pu, I. S. Amiinu, C. Zhang, M. Wang, Z. Kou and S. Mu, Nanoscale, 2017, 9, 3555-3560.

31 Z. Pu, I. S. Amiinu, Z. Kou, W. Li and S. Mu, Angew. Chem., Int. Ed., 2017, 56, 11559-11564.

32 A. Han, H. Zhang, R. Yuan, H. Ji and P. Du, ACS Appl. Mater. Interfaces, 2017, 9, 2240-2248.

33 L. A. Stern, L. G. Feng, F. Song and X. L. Hu, Energy Environ. Sci., 2015, 8, 2347-2351.

34 H. H. Zou, C. Z. Yuan, H. Y. Zou, T. Y. Cheang, S. J. Zhao, U. Y. Qazi, S. L. Zhong, L. Wang and A. W. Xu, Catal. Sci. Technol., 2017, 7, 1549-1555.

35 N. Jiang, B. You, M. Sheng and Y. Sun, Angew. Chem., Int. Ed., 2015, 54, 6251-6254.

36 G.-F. Chen, T. Y. Ma, Z.-Q. Liu, N. Li, Y.-Z. Su, K. Davey and S.-Z. Qiao, Adv. Funct. Mater., 2016, 26, 3314-3323.

37 P. Zhang, B. Y. Guan, L. Yu and X. W. D. Lou, Angew. Chem., Int. Ed., 2017, 56, 7141-7145.

38 L. Yu, J. F. Yang, B. Y. Guan, Y. Lu and X. W. D. Lou, Angew. Chem., Int. Ed., 2018, 57, 172-176.

39 C. C. Du, M. X. Shang, J. X. Mao and W. B. Song, J. Mater. Chem. A, 2017, 5, 15940-15949.

40 C. Tang, R. Zhang, W. Lu, Z. Wang, D. Liu, S. Hao, G. Du, A. M. Asiri and X. Sun, Angew. Chem., Int. Ed., 2017, 56, 842.

41 H. J. Zhang, X. P. Li, A. Hahnel, V. Naumann, C. Lin, S. Azimi, S. L. Schweizer, A. W. Maijenburg and R. B. Wehrspohn, Adv. Funct. Mater., 2018, 28, 1706847.

42 E. L. Hu, Y. F. Feng, J. W. Nai, D. Zhao, Y. Hu and X. W. Lou, Energy Environ. Sci., 2018, 11, 872-880.

43 L. T. Yan, L. Cao, P. C. Dai, X. Gu, D. D. Liu, L. J. Li, Y. Wang and X. B. Zhao, Adv. Funct. Mater., 2017, 27, 1703455.

44 C. Chen, Y. Kang, Z. Huo, Z. Zhu, W. Huang, H. L. Xin, J. D. Snyder, D. Li, J. A. Herron, M. Mavrikakis, M. Chi, K. L. More, Y. Li, N. M. Markovic, G. A. Somorjai, P. Yang and V. R. Stamenkovic, Science, 2014, 343, 1339-1343.

45 X. Wang, J. Feng, Y. Bai, Q. Zhang and Y. Yin, Chem. Rev., 2016, 116, 10983-11060.
46 Y. Bai, L. Fang, H. Xu, X. Gu, H. Zhang and Y. Wang, Small, 2017, 13, 1603718.

47 Z. S. Cai, Y. Shi, S. S. Bao, Y. Shen, X. H. Xia and L. M. Zheng, ACS Catal., 2018, 8, 3895-3902.

48 Z. Cao, T. T. Zhou, W. Xi and Y. F. Zhao, Electrochim. Acta, 2018, 263, 576-584.

49 M. Zhuang, X. Ou, Y. Dou, L. Zhang, Q. Zhang, R. Wu, Y. Ding, M. Shao and Z. Luo, Nano Lett., 2016, 16, 4691-4698.

50 C. Xia, Q. Jiang, C. Zhao, M. N. Hedhili and H. N. Alshareef, Adv. Mater., 2016, 28, 77-85.

51 X. L. Ge, Z. Q. Li and L. W. Yin, Nano Energy, 2017, 32, 117124.

52 Y. P. Li, J. D. Liu, C. Chen, X. H. Zhang and J. H. Chen, ACS Appl. Mater. Interfaces, 2017, 9, 5982-5991.

53 M. C. Biesinger, B. P. Payne, A. P. Grosvenor, L. W. M. Lau, A. R. Gerson and R. S. Smart, Appl. Surf. Sci., 2011, 257, 2717-2730.

54 X. Y. Yu, Y. Feng, B. Y. Guan, X. W. Lou and U. Paik, Energy Environ. Sci., 2016, 9, 1246-1250.

55 B. Y. Guan, L. Yu and X. W. Lou, Angew. Chem., Int. Ed., 2017, 56, 2386-2389.

56 M. Xu, L. Han, Y. Han, Y. Yu, J. Zhai and S. Dong, J. Mater. Chem. A, 2015, 3, 21471-21477.

57 M. Liu and J. Li, ACS Appl. Mater. Interfaces, 2015, 8, 21582165.

58 R. Zhang, X. Wang, S. Yu, T. Wen, X. Zhu, F. Yang, X. Sun, X. Wang and W. Hu, Adv. Mater., 2017, 29, 1605502.

59 P. He, X. Y. Yu and X. W. Lou, Angew. Chem., Int. Ed., 2017, 56, 3897-3900.

60 Y. W. Tan, H. Wang, P. Liu, Y. H. Shen, C. Cheng, A. Hirata, T. Fujita, Z. Tang and M. W. Chen, Energy Environ. Sci., 2016, 9, 2257-2261.

61 J. Yu, Q. Q. Li, Y. Li, C. Y. Xu, L. Zhen, V. P. Dravid and J. S. Wu, Adv. Funct. Mater., 2016, 26, 7644-7651.

62 X. D. Wang, Y. F. Xu, H. S. Rao, W. J. Xu, H. Y. Chen, W. X. Zhang, D. B. Kuang and C. Y. Su, Energy Environ. Sci., 2016, 9, 1468-1475.

63 Z. Pu, C. Zhang, I. S. Amiinu, W. Li, L. Wu and S. Mu, ACS Appl. Mater. Interfaces, 2017, 9, 16187-16193.

64 T. H. Zhou, Y. H. Du, S. M. Yin, X. Z. Tian, H. B. Yang, X. Wang, B. Liu, H. M. Zheng, S. Z. Qiao and R. Xu, Energy Environ. Sci., 2016, 9, 2563-2570.

65 J. Nai, Y. Lu, L. Yu, X. Wang and X. W. D. Lou, Adv. Mater., 2017, 29, 1703870.

66 X. Y. Yu, L. Yu, H. B. Wu and X. W. Lou, Angew. Chem., Int. Ed., 2015, 54, 5331-5335.

67 L. Han, X. Y. Yu and X. W. Lou, Adv. Mater., 2016, 28, 46014605.

68 J. Nai, B. Y. Guan, L. Yu and X. W. D. Lou, Sci. Adv., 2017, 3, e1700732.

69 J. Nai, J. Zhang and X. W. Lou, Chem, 2018, 4, 1967-1982.

70 J. Nai and X. W. D. Lou, Adv. Mater., 2018, DOI: 10.1002/ adma.201706825.

71 J. Nai, Y. Lu, L. Yu, X. Wang and X. W. D. Lou, Adv. Mater., 2017, 29, 1703870.

72 M. H. Sun, S. Z. Huang, L. H. Chen, Y. Li, X. Y. Yang, Z. Y. Yuan and B. L. Su, Chem. Soc. Rev., 2016, 45, 3479-3563. 
73 C. M. Parlett, K. Wilson and A. F. Lee, Chem. Soc. Rev., 2013, 42, 3876-3893.

74 H. B. Wu, B. Y. Xia, L. Yu, X. Y. Yu and X. W. Lou, Nat. Commun., 2015, 6, 6512.

75 Z. Pu, I. Saana Amiinu, M. Wang, Y. Yang and S. Mu, Nanoscale, 2016, 8, 8500-8504.

76 J. Hao, W. Yang, Z. Zhang and J. Tang, Nanoscale, 2015, 7, 11055-11062.

77 J. Kibsgaard, C. Tsai, K. Chan, J. D. Benck, J. K. Norskov, F. Abild-Pedersen and T. F. Jaramillo, Energy Environ. Sci., 2015, 8, 3022-3029.
78 C. Tang, L. Gan, R. Zhang, W. Lu, X. Jiang, A. M. Asiri, X. Sun, J. Wang and L. Chen, Nano Lett., 2016, 16, 6617-6621.

79 Y. Shi and B. Zhang, Chem. Soc. Rev., 2016, 45, 1781.

80 P. Liu and J. A. Rodriguez, J. Am. Chem. Soc., 2005, 127, 14871-14878.

81 P. Xiao, M. A. Sk, L. Thia, X. M. Ge, R. J. Lim, J. Y. Wang, K. H. Lim and X. Wang, Energy Environ. Sci., 2014, 7, 26242629.

82 J. Ryu, N. Jung, J. H. Jang, H. J. Kim and S. J. Yoo, ACS Catal., 2015, 5, 4066-4074. 